\title{
Epidemiology, virology, and clinical features of severe acute respiratory syndrome -coronavirus-2 (SARS-CoV-2; Coronavirus Disease-19)
}

\author{
Su Eun Park, MD, PhD \\ Department of Pediatrics, Pusan National University College of Medicine, Yangsan, Korea
}

A cluster of severe pneumonia of unknown etiology in Wuhan City, Hubei province in China emerged in December 2019. A novel coronavirus named severe acute respiratory syndrome coronavirus-2 (SARS-CoV-2) was isolated from lower respiratory tract sample as the causative agent. The current outbreak of infections with SARS-CoV-2 is termed Coronavirus Disease 2019 (COVID-19) by the World Health Organization (WHO). COVID-19 rapidly spread into at least 114 countries and killed more than 4,000 people by March 112020 . WHO officially declared COVID-19 a pandemic on March 11, 2020. There have been 2 novel coronavirus outbreaks in the past 2 decades. The outbreak of severe acute respiratory syndrome (SARS) in 2002-2003 caused by SARS-CoV had a case fatality rate of around 10\% (8,098 confirmed cases and 774 deaths), while Middle East respiratory syndrome (MERS) caused by MERSCoV killed 861 people out of a total 2,502 confirmed cases between 2012 and 2019. The purpose of this review is to summarize known-to-date information about SARS-CoV-2, transmission of SARS-CoV-2, and clinical features.

Key words: SARS-CoV-2, COVID-19, Coronavirus, SARSCoV, MERS-CoV

\section{Introduction}

In December 2019, a cluster of patients with pneumonia of unknown origin was identified in Wuhan, Hubei Province, China. Most patients witnessed a history of visiting Huanan Seafood Wholesale Market. On December 31, 2019, the Chinese Center for Disease Control and Prevention (China CDC) and Wuhan City health authorities reported an outbreak of pneumonia of unknown causes in Wuhan City. ${ }^{1,2)}$ On January 7 , 2020, the China CDC identified a novel coronavirus from the lower respiratory tract samples of the patients with pneumonia and disclosed the genomic sequence on January $11 .^{3,4)}$ This novel coronavirus was later named severe acute respiratory syndrome coronavirus-2 (SARS-CoV-2). The World Health Organization (WHO) named this infection, caused by SARS-CoV-2 identified in 2019, Coronavirus Disease 2019 (COVID-19). ${ }^{5)}$ Despite the effort to stop the transmission of COVID-19, the infection spread throughout mainland China, and in January 2020, cases were reported in Thailand, Japan, and South Korea. ${ }^{6,7)}$ Within less than 3 months since the discovery of the unknown pathogen, the infection spread to at least 114 countries and caused more than 4,000 deaths. On March 11, the WHO announced COVID-19 outbreak a pandemic. ${ }^{8)}$ In South Korea, the first case was identified on January 20, 20207), and as of March 26, a total of 9,241 confirmed cases leading to 131 deaths $(1.42 \%$ fatality rate) has been reported. ${ }^{9)}$

Two novel strains of coronavirus have jumped species from animal to human, spread by human-to-human transmission, and caused severe acute respiratory syndrome leading to high fatality rate in the past 2 decades. ${ }^{10)}$ Severe acute respiratory syndrome-associated virus (SARS-CoV), previously unknown coronavirus traced to horseshoe bats in southern China, caused 8,096 confirmed cases and 774 deaths (9.6\% fatality rate) in 29 countries from November 2002 to July 2003. ${ }^{11)}$ In South Korea, the first suspected case was reported in April 3, 2003. As of June 15, 2003, three probable cases and 17 suspected cases were identified without any fatality. ${ }^{12)}$ Globally, no SARS-CoV infection has been reported since 2004. ${ }^{10)}$ In 2012, another novel coronavirus was first identified in a patient with acute severe respiratory syndrome and multiple organ failure in Saudi Arabia. ${ }^{13)}$ This pathogen, later named MERS-CoV, associated with pneumonia and acute respiratory syndrome (Middle East respiratory syndrome), leading to an outbreak in Arabian Peninsula. Between April 2012 and December 2019, a total of 2,502 confirmed cases and 861 deaths (34.4\% fatality rate) were reported in 27 countries. $^{14)}$ In May 2015, a returned traveler from Saudi Arabia was linked to 186 confirmed MERS-CoV infections and 38 deaths (20.4\% fatality rate) in South Korea. ${ }^{15)}$

This article reviews characteristics, pattern of transmission, and clinical features of COVID-19. We also briefly describe

Corresponding author: Su Eun Park, MD, PhD. Department of Pediatrics, Pusan National University College of Medicine, 20 Geumo-ro, Yangsan 50612, Korea 凶E-mail: psepse@naver.com, https://orcid.org/0000-0001-5860-821X

Received: 27 March, 2020, Revised: 2 April, 2020, Accepted: 2 April, 2020

This is an open-access article distributed under the terms of the Creative Commons Attribution Non-Commercial License (http://creativecommons.org/licenses/bync/4.0/) which permits unrestricted non-commercial use, distribution, and reproduction in any medium, provided the original work is properly cited.

Copyright (c) 2020 by The Korean Pediatric Society 
Table 1. Differences in characteristics of COVID-19, SARS, and MERS

\begin{tabular}{|c|c|c|c|}
\hline Characteristic & COVID-19 & SARS & MERS \\
\hline First identified location & Wuhan, China & Guangdong, China & Jeddah, Saudi Arabia \\
\hline Period & 2019-present & $2002-2003$ & 2012-ongoing \\
\hline \multicolumn{4}{|l|}{ Host of virus } \\
\hline Natural host & Bats & Bats & Bats \\
\hline Intermediate host & Unknown & Civet cat or other animal hosts & Dromedary camels \\
\hline Mode of transmission & Respiratory droplet, contact & Respiratory droplet, contact & Respiratory droplet, contact \\
\hline$R_{0}$ & $2-3$ & $2-5^{46)}$ & $<1^{46)}$ \\
\hline Incubation period & Median 5.1 days (95\% Cl, 2.2-11.5) & Mean 4.6 days $^{47)}(95 \% \mathrm{Cl}, 3.8-5.8)$ & Median 5.2 days $^{47)}(95 \% \mathrm{Cl}, 1.9-14.7)$ \\
\hline Case fatality rate & $3.8 \%{ }^{43)}$ & $9.6 \%$ & $34.4 \%$ \\
\hline
\end{tabular}

COVID-19, coronavirus disease-2019; SARS, severe acute respiratory syndrome; MERS, Middle East respiratory syndrome; $R$, basic reproduction number; Cl, confidence interval.

distinct features of SARS-CoV-2 in comparison to SARS-CoV and MERS-CoV (Table 1).

\section{Characteristics and taxonomy of the virus}

Coronaviruses are enveloped positive sense single-stranded RNA viruses sized $80-220 \mathrm{~nm}$ in diameter. The envelop bears crown-like, 20-nm in length spikes that resemble corona of the sun under electron microscopy, hence given its name coronavirus. The virus can cause disease both in animal and human. It carries the largest genome among the currently known RNA viruses. ${ }^{16}$ ) Coronaviruses are members of the subfamily Coronavirinae in the family Coronaviridae and the order Nidovirales. This subfamily divides into 4 genera - alphacoronavirus, betacoronavirus, gammacoronavirus, and deltacoronavirus. So far, 6 coronaviruses are known to cause human diseases. Four coronaviruses are endemic in humans. These are human coronaviruses $(\mathrm{HCoV})$ 229E, OC43, NL63, and HKU1. Two epidemic human coronaviruses are SARS-CoV and MERS-CoV. Alphacoronavirus includes $\mathrm{HCoV} 229 \mathrm{E}$ and NL63, and betacoronavirus includes $\mathrm{HCoV}$ OC43, HKU1, SARS-CoV, and MERS-CoV. The gammacoronavirus includes avian infectious bronchitis virus and several other coronaviruses, and deltacoronavirus includes several recently discovered avian coronavirus.

Within the coronavirus particle, a nucleoprotein $(\mathrm{N})$ wraps the RNA genome to form a coiled tubular structure together. The viral envelop (E) surround this helical nucleocapsid. Two or 3 structural proteins are associated with viral envelop. The matrix protein (M) embedded in envelop. The spike structural protein $(\mathrm{S})$ anchored in envelop is target of neutralizing antibody. The hemagglutinin esterase is found in several of the betacoronaviruses. ${ }^{17)}$ The coronaviruses have 5 essential genes which are for 4 structural proteins (N, E, M, S) and for viral replication/ transcription (RNA dependent RNA polymerase, RdRp). The genome organization is 5'-RdRp-S-E-M-N-3'. This gene order of coronaviruses is highly conserved. ${ }^{17)}$

Whole genome sequencing of SARS-CoV-2 reveals that it is a novel betacoronavirus distinct from SARS-CoV. ${ }^{18)}$ The nucleotide sequence of SARS-CoV-2 showed $79.0 \%$ and 51.8
$\%$ identity with SARS-CoV and MERS-CoV, respectively and it is closely related to bat-origin SARS-like coronavirus (batSL-CoVZC45) with $87.6 \%-89 \%$ identity. ${ }^{19,20)}$ The virus was initially called 2019-novel coronavirus (2019-nCoV) upon its emergence, until the Coronaviridae Study Group of International Committee on Taxonomy of Viruses named the virus severe acute respiratory syndrome coronavirus-2 (SARS-CoV-2) based on the phylogenetic analysis, on February 11, 2020.21) On the same day, the WHO named the disease caused by the novel coronavirus Coronavirus Disease 2019 (COVID-19), in alignment with $\mathrm{WHO}$ best practices for naming of new human infectious disease. ${ }^{5)}$

Based on the virus genome sequencing data, bats are assumed to be the reservoir of SARS-CoV-2, but the intermediate hosts are yet to be known. Data indicate SARS-CoV evolved from bat coronavirus in horseshoe bats through civet cats or other intermediated animal hosts. MERS-CoV also likely evolved from bat coronavirus, with dromedary camels as intermediate hosts. ${ }^{22-25)}$

SARS-CoV-2 gains entry to a host cell through binding its spike proteins, which determine host tropism, to host cell receptors. ${ }^{26)}$ Preliminary researches had suggested that SARS-CoV-2 might share a host cell receptor with SARS-CoV, because the 2 strains have similar receptor-binding protein structures. Successive studies showed that SARS-CoV-2 binds to angiotensin converting enzyme 2 (ACE2) as SARS-CoV does. ${ }^{27,28)} \mathrm{HCoV}$ NL63 also binds to ACE2, but with less avidity than SARS-CoV; HCoV 229E binds to aminopeptidase N (CD-13); receptor for $\mathrm{HCoV}$ OC43 is still unknown; MERS-CoV binds to dipeptidyl peptidase-4. ${ }^{28}$

SARS-CoV-2 was first isolated from a bronchoalveolar lavage sample, ${ }^{18)}$ and RNA of the virus was also detected in nasopharyngeal and throat swabs as well as blood, stool, urine, and saliva. ${ }^{29,30)}$

\section{Transmission of the virus}

When COVID-19 first emerged in Wuhan, China, no infection of healthcare personnel had been reported, and human-tohuman transmission of the virus was considered unlikely until 
patients unrelated to the seafood market began to appear. As community transmission cases and outbreaks outside China were reported, human-to-human transmission became apparent. ${ }^{20,31)}$

Mode of transmission for HCoV 229E, OC43, NL63, and HKU1 are not clearly known, but as with other respiratory viruses, human coronavirus transmission occurs via droplets, indirect or direct contacts. ${ }^{16)}$ Possibility of aerosol transmission remains to be investigated. MERS-CoV spreads mostly through droplet and direct contact, but transmission through indirect contact, aerosol, fecal-to-oral route is also possible. ${ }^{10,16)}$ SARS$\mathrm{CoV}$ primarily spreads via droplet and direct contact. Medical procedures that induce production of aerosol, such as nebulizer treatment or intubation, are reported to increase the risk of transmission. Fecal-to-oral route may be possible, but little evidence supports it. ${ }^{10)}$ SARS-CoV-2 seems to share the mode of transmission with SARS-CoV and MERS-CoV, as it spreads mainly through respiratory secretion or droplet. Recent studies showed that SARS-CoV-2 can remain viable on various surfaces such as stainless steel, plastic, glass, and cardboard at least several hours. ${ }^{32,33)}$ This indicates that transmission of SARS-CoV-2 through contaminated surfaces might be possible. Aerosol is currently not considered as primary mode of transmission since no airborne transmission has been reported yet, although it seems possible in hospital settings where aerosol-producing procedures occur. SARS-CoV-2 RNA has been detected in stool, whole blood and urine of COVID-19 patients, but whether transmission via such medium is possible is still unknown. ${ }^{29)}$

SARS-CoV-2 is more rapidly spreading across the globe than SARS-CoV did. Within 3 months since the initial report of outbreak in Wuhan, 80,555 confirmed cases in China and 17,821 confirmed cases in 90 countries outside of China had occurred by March 5, 2020. On March 11, COVID-19 had spread to at least 114 countries around the globe and had killed more than 4,000 lives. On the same day, the WHO declared COVID-19 a pandemic. ${ }^{8}$ It is notable that SARS-CoV infection was not declared a pandemic despite of 8,096 confirmed cases leading to 774 deaths during the 8 -month period since the first report of SARS case on November 16, 2002. Meanwhile, in April 2009, when H1N1pdm09 virus spread rapidly around the globe and caused more than 30,000 cases in 74 countries, the WHO announced H1N1pdm09 influenza virus infection a pandemic. ${ }^{34)}$

The transmissibility of SARS-CoV-2 is not precisely known. A meta-analysis of 12 studies published between January 1 and February 7, 2020 suggests that basic reproduction number $\left(R_{0}\right)$ of SARS-CoV-2 ranged from 1.4 to 6.49 (mean, 3.23; median, 2.79). ${ }^{35)}$ Accumulation of more epidemiologic data may modify this value, but $R_{0}$ is expected to be around between 2 and 3 .

SARS-CoV transmission occurs several days after the onset of symptoms, in alignment with the period of peak respiratory viral load. ${ }^{10)}$ SARS-CoV was effectively contained by isolating the patient soon after the onset of illness, since secondary attack rate was greatly reduced by isolating the index case within 5 days. On the other hand, the point of transmission for SARS-
CoV-2 remains unknown. In general, respiratory viruses have the highest transmissibility when the patient has symptoms, therefore we assume the same for COVID-19. According to a study that followed respiratory viral load of 18 COVID-19 patients in China, viral load peaks shortly after the onset of illness and declines there on. ${ }^{36}$ ) The viral nucleic acid shedding pattern of patients infected with SARS-CoV-2 resembles that of patients with influenza virus. The study results suggested that transmission of COVID-19 may occur during first few days after the onset of symptoms. Moreover, the number of virus RNA copies from one asymptomatic case was comparable to that of the rest of symptomatic cases. In addition, a case of transmission from an asymptomatic family member was recently reported. ${ }^{37)}$ Therefore, we can assume that transmission of COVID-19 may occur with the illness onset and even with mild or no symptoms. However, further research is needed on viral transmission from an asymptomatic patient because there is a possibility that the patient may not have been aware of his or her symptoms or may not have been recognized by caregivers due to old age or underlying illness of the patient. The pattern of transmission observed in COVID-19 is distinctive from that of SARS-CoV; such pattern indicates that the spread may not be effectively controlled by isolating the patient after the illness onset. Transmissibility of the virus during incubation period is yet to be established.

Little is known about vertical transmission of COVID-19. In a study of 12 SARS-CoV infected pregnant women during outbreak in 2002-2003, 3 women (25\% case fatality rate) died and 4 had spontaneous miscarriage. ${ }^{38)}$ Five mothers delivered; 4 by caesarean section and 1 by spontaneous vaginal delivery. Gestational ages ranged 26-37 weeks. All 5 newborns did not show evidence of SARS-CoV infection, but 2 newborns out of 5 had intrauterine growth retardation. Another study analyzed several reports about pregnancy and perinatal outcome of MERS$\mathrm{CoV}$ infected pregnant women ${ }^{39}$; of the total 9, 5 mothers received intensive care, and 3 out of 5 them died $(33.3 \%$ case fatality rate). Two women had spontaneous miscarriage, and 5 mothers delivered at gestational age between 32 to term; none of the newborns had signs of MERS-CoV infection. Chen et al. ${ }^{40)}$ analyzed 9 pregnant women who had been diagnosed with COVID-19 in their third trimester and had caesarean section. Clinical features of mothers and their newborns were recorded, along with SARS-CoV-2 detection in amniotic fluid, cord blood, breastmilk, and nasopharyngeal swab of the newborn. None of the 9 mothers developed severe pneumonia, died or had miscarriage. All the amniotic fluid, cord blood, breastmilk, and nasopharyngeal swab of the newborn tested negative for SARS-CoV-2. This study suggested that there is currently no evidence of vertical transmission of SARS-CoV-2 in women who developed pneumonia during 3rd trimester of pregnancy. However, the number of pregnant women of the study is very small and only the infection in the late of pregnancy is included, so it cannot be concluded at the moment on the impact of the infection especially in the early or mid-term pregnancy on preg. nant women and fetuses. 


\section{Clinical features of COVID-19}

The median incubation period was 5.1 days, ${ }^{41)}$ ranged from 2-14 days. ${ }^{31)}$ An analysis of household transmissions revealed that fever and respiratory symptoms appeared 3-7 days after exposure to the virus. Fever, dry cough, and fatigue were more commonly reported, whereas nasal congestion, rhinorrhea, sore throat, and myalgia were relatively rare. ${ }^{42)}$ Occasionally, nonrespiratory symptoms such as palpitation, diarrhea, or headache preceded respiratory symptoms. Some patients were initially afebrile. Clinical spectrum of COVID-19 ranged from asymptomatic to fatal pneumonia. The rate of asymptomatic infection is yet to be defined, since most initially asymptomatic infections eventually turned symptomatic.

Based on the data from the Chinese National Reporting System, as of February 20, 2020, the median age of the confirmed cases was 51 years ( 2 days-100 years), of which $77.8 \%$ were 30 69 years. ${ }^{43)}$ A total of $51.1 \%$ were male. Of the reported confirm. ed cases, $80 \%$ were without pneumonia, or had mild to moderate pneumonia; approximately $15 \%$ had severe pneumonia; approximately $6 \%$ were under intensive care due to respiratory failure, shock, or multiple organ failure. Fatality rate of COVID-19 in China is $3.8 \%$; the fatality rate in Wuhan City is $5.8 \%$, in comparison to that of $0.7 \%$ in the rest of mainland China. Risk factors of severe pneumonia or death include ages 60 or older, and medical comorbidity such as hypertension, diabetes mellitus, cardiovascular disease, chronic pulmonary disease or malignancy. Laboratory tests of the confirmed COVID-19 cases showed leukopenia, lymphopenia, mild elevated C-reactive protein. But the patients with severe pneumonia had elevations in leukocytes, neutrophils, and creatinine kinase. Computed tomography of the chest revealed ground glass appearance, interstitial infiltration, or multiple patchy consolidations in both lung fields. ${ }^{44)}$

A group of researchers in Wuhan City analyzed 138 hospitalized patients based on the severity of pneumonia. ${ }^{45)}$ Among the 138 patients with pneumonia, 36 required intensive care. The median age of the intensive care group was 66 years, while that of the other group was 51 years. The intensive care group was more likely to have underlying conditions including hypertension and diabetes mellitus. The median time from onset of symptoms to dyspnea was 5 days and to acute respiratory syndrome was 8 days. At the point of publication, 6 patients had died with overall mortality of $4.3 \%$. In fatal cases, elevations in total leukocyte count, neutrophil ratio, and decrease in lymphocyte were observed 7 days after the onset of symptoms.

Meanwhile, SARS-CoV infection most commonly presents with fever. The infection begins with systemic complaints including myalgia, chills, or fatigue, followed by dry cough and dyspnea after a few days to a week. Symptoms of upper respiratory tract infection such as rhinorrhea or sore throat are rare. Watery diarrhea may be accompanied in 10\%-25\% patients in later course of the disease. Intensive care was required in $20 \%$
$30 \%$ of patients, with $10 \%$ fatality rate. In ages older than 60 years, fatality rate was 50\%. Death mostly occurred in the third week from the onset of symptoms. In MERS-CoV infections, the disease course is especially severe in patients with preexisting conditions such as renal failure. Cough and dyspnea appear a few days after the onset of symptoms; plain chest radiographs reveal infiltrations in unilateral or bilateral lung fields; the symptoms aggravate rapidly, and ventilator care ensues. Fatality rate was $35 \%$. Vomiting, diarrhea, or abdominal pain was accompanied in approximately $25 \%$ of cases. ${ }^{10)}$

\section{Conclusion}

Within 3 months since the discovery of a novel coronavirus in patients with pneumonia of unknown origin in Wuhan City, China, COVID-19 has spread rapidly throughout the world and is beating SARS-CoV and MERS-CoV in the number of confirmed cases and deaths. Modern medical knowledge and technology enabled us to promptly identify the previously unknown pathogen, share the genomic information of the virus, develop diagnostic tools, detect the disease, isolate patients, and provide appropriate medical care. However, several unanswered questions remain to be addressed: the reservoir and intermediate hosts of SARS-CoV-2, the peak periods of transmission, the duration of transmission, and pathogenesis of severe pneumonia. The world needs to not only strive to slow the spread but also invest in development of treatment and vaccines for COVID-19.

\section{Conflicts of interest}

No potential conflict of interest relevant to this article was reported.

\section{Acknowledgments}

I would like to thank all the members of the Committee on Infectious Diseases of the Korean Pediatric Society and the Korean Society of Pediatric Infectious Diseases for their efforts in searching and analyzing the data related with SARS-CoV-2.

This review article is published jointly by the Clinical and experimental Pediatrics and the Pediatric Infection and Vaccine.

\section{References}

1. Lu H, Stratton CW, Tang YW. Outbreak of pneumonia of unknown etiology in Wuhan, China: The mystery and the miracle. J Med Virol 2020;92:401-2.

2. World Health Organization. Situation Report 12020 (World Health Organization. Novel coronavirus (2019-nCoV), situation report-1. 21 January 2020 [Internet]. Geneva (Switzerland): World Health Organization; 2020 [cited 2020 Mar 2]. Available from: https://www.who.int/ docs/default-source/coronaviruse/situation-reports/20200121-sitrep-12019-ncov.pdf.

3. GISAID Database. 2020 coronavirus [Internet]. Munich (Germany): GISAID Database; 2020 [cited 2020 Mar 20]. Available from: https:// www.gisaid.org/CoV2020. 
4. Paraskevis D, Kostaki EG, Magiorkinis G, Panayiotakopoulos G, Sourvinos G, Tsiodras S. Full-genome evolutionary analysis of the novel corona virus (2019-nCoV) rejects the hypothesis of emergence as a result of a recent recombination event. Infect Genet Evol 2020;79:104212.

5. World Health Organization. WHO Director-General's remarks at the media briefing on 2019-nCoV on 11 February 2020 [Internet]. Geneva (Switzerland): World Health Organization; 2020 [cited 2020 Mar 12]. Available from: https://www.who.int/dg/speeches/detail/whodirector-general-s-remarks-at-the-media-briefing-on-2019-ncov-on-11february-2020.

6. Gralinski LE, Menachery VD. Return of the Coronavirus: 2019-nCoV. Viruses 2020 Jan 24;12(2). pii: E135. https://doi.org/10.3390/v12020135.

7. Kim JY, Choe PG, Oh Y, Oh KJ, Kim J, Park SJ, et al. The First Case of 2019 Novel Coronavirus Pneumonia Imported into Korea from Wuhan, China: implication for infection prevention and control measures. J Korean Med Sci 2020;35:e61.

8. World Health Organization. WHO Director-General's opening remarks at the media briefing on COVID-19 - 11 March 2020 [Internet]. Geneva (Switzerland): World Health Organization; 2020 [cited 2020 Mar 11]. Available from: https://www.who.int/dg/speeches/detail/who-director-general-sopening-remarks-at-the-media-briefing-on-covid-19---11-march- 2020.

9. Korea Centers for Disease Control and Prevention. Updates on COVID19 in Republic of Korea [Internet]. Cheongju (Korea): Korea Centers for Disease Control and Prevention; 2020 March [cited 2020 Apr 1]. Available from: https://is.cdc.go.kr/upload comm/syview/doc.html?fn= 158522019760700.pdf\&rs=/upload_comm/docu/0030/.

10. American Academy of Pediatrics. Coronaviruses, including SARS and MERS. In: Kimberlin DW, Brady MT, Jackson MA, Long SS, editors. Red Book®: 2018 Report of the Committee on Infectious Diseases. 31st ed. Itasca (IL): American Academy of Pediatrics, 2018:297-301.

11. World Health Organization. Summary of probable SARS cases with onset of illness from 1 November 2002 to 31 July 2003 [Internet]. Geneva (Switzerland): World Health Organization; 2003 Dec [cited 2020 Apr 1]. Available from: https://www.who.int/csr/sars/country/table2004_04_21/ en/.

12. Lee JS. Severe acute respiratory syndrome (SARS) In: Yoo JH, editor. Infectious disease. Seoul (Korea): Koonja, 2007:775-81.

13. Zaki AM, van Boheemen S, Bestebroer TM, Osterhaus AD, Fouchier RA. Isolation of a novel coronavirus from a man with pneumonia in Saudi Arabia. NEngl J Med 2012;367:1814-20.

14. World Health Organization. MERS situation update, December 2019 [Internet]. Geneva (Switzerland): World Health Organization; 2019 Dec [cited 2020 Apr 1]. Available from: http://www.emro.who.int/pandemicepidemic-diseases/mers-cov/mers-situation-update-december-2019.html.

15. Oh MD, Park WB, Park SW, Choe PG, Bang JH, Song KH, et al. Middle East respiratory syndrome: what we learned from the 2015 outbreak in the Republic of Korea. Korean J Intern Med 2018;33:233-46.

16. Englund JA, Kim YJ, McIntosh K. Human coronaviruses, including Middle East respiratory syndrome coronavirus. In: Cherry J, DemmlerHarrison GJ, Kaplan SL, Steinbach WJ, Hotez PJ, editors. Feigin and Cherry's textbook of pediatric infectious disease. 8th ed. Philadelphia (PA): Elsevier Inc., 2019:1846-54.

17. Brian DA, Baric RC. Coronavirus genome structure and replication. In: Enjuanes L, editor. Coronavirus replication and reverse genetics. Berlin (Germany): Springer, 2005:1-30.

18. Zhu N, Zhang D, Wang W, Li X, Yang B, Song J, et al. A novel coronavirus from patients with pneumonia in China, 2019. N Engl J Med 2020;382: 727-33.

19. Ren LL, Wang YM, Wu ZQ, Xiang ZC, Guo L, Xu T, et al. Identification of a novel coronavirus causing severe pneumonia in human: a descriptive study. Chin Med J (Engl) 2020 Feb 11 [Epub]. https://doi.org/10.1097/ CM9.0000000000000722.

20. Chan JF, Yuan S, Kok KH, To KK, Chu H, Yang J, et al. A familial cluster of pneumonia associated with the 2019 novel coronavirus indicating personto-person transmission: a study of a family cluster. Lancet 2020;395:51423.

21. Coronaviridae Study Group of the International Committee on Taxonomy of Viruses. The species Severe acute respiratory syndrome-related coronavirus: classifying 2019-nCoV and naming it SARS-CoV-2. Nat Microbiol 2020;5:536-44.

22. Kan B, Wang M, Jing H, Xu H, Jiang X, Yan M, et al. Molecular evolution analysis and geographic investigation of severe acute respiratory syndrome coronavirus-like virus in palm civets at an animal market and on farms. J Virol 2005;79:11892-900.

23. Lau SK, Woo PC, Li KS, Huang Y, Tsoi HW, Wong BH, et al. Severe acute respiratory syndrome coronavirus-like virus in Chinese horseshoe bats. Proc Natl Acad Sci US A 2005;102:14040-5.

24. Anthony SJ, Gilardi K, Menachery VD, Goldstein T, Ssebide B, Mbabazi $\mathrm{R}$, et al. Further evidence for bats as the evolutionary source of Middle East respiratory syndrome coronavirus. mBio 2017 Apr 4;8(2). pii: e00373-17. https://doi.org/10.1128/mBio.00373-17.

25. Drosten C, Kellam P, Memish ZA. Evidence for camel-to-human trans mission of MERS coronavirus. NEngl J Med 2014;371:1359-60.

26. Belouzard S, Millet JK, Licitra BN, Whittaker GR. Mechanisms of coronavirus cell entry mediated by the viral spike protein. Viruses 2012; 4:1011-33

27. Letko M, Marzi A, Munster V. Functional assessment of cell entry and receptor usage for SARS-CoV-2 and other lineage B betacoronaviruses. Nat Microbiol 2020;5:562-9.

28. Zhang H, Penninger JM, Li Y, Zhong N, Slutsky AS. Angiotensinconverting enzyme 2 (ACE2) as a SARS-CoV-2 receptor: molecular mechanisms and potential therapeutic target. Intensive Care Med 2020; 46:586-90.

29. Young BE, Ong SWX, Kalimuddin S, Low JG, Tan SY, Loh J, et al. Epidemiologic features and clinical course of patients infected with SARSCoV-2 in Singapore. JAMA 2020 Mar 3 [Epub]. https://doi.org/10.1001/ jama.2020.3204.

30. To KK, Tsang OT, Chik-Yan Yip C, Chan KH, Wu TC, Chan JMC, et al. Consistent detection of 2019 novel coronavirus in saliva. Clin Infect Dis 2020 Feb 12 [Epub]. pii: ciaa149. https://doi.org/10.1093/cid/ciaa149.

31. Li Q, Guan X, Wu P, Wang X, Zhou L, Tong Y, et al. Early transmission dynamics in Wuhan, China, of novel coronavirus-infected pneumonia. $\mathrm{N}$ Engl J Med 2020;382:1199-207.

32. Ong SWX, Tan YK, Chia PY, Lee TH, Ng OT, Wong MSY, et al. Air, surface environmental, and personal protective equipment contamination by severe acute respiratory syndrome coronavirus 2 (SARS-CoV-2) from a symptomatic patient. JAMA 2020 Mar 4 [Epub]. https://doi.org/10.1001/ jama.2020.3227.

33. van Doremalen N, Bushmaker T, Morris DH, Holbrook MG, Gamble A, Williamson BN, et al. Aerosol and Surface Stability of SARS-CoV-2 as Compared with SARS-CoV-1. N Engl J Med 2020 Mar 17 [Epub]. https://doi.org/10.1056/NEJMc2004973.

34. World Health Organization. World now at the start of 2009 influenza pandemic [Internet]. Geneva (Switzerland): World Health Organization; 2019 Jun [cited 2020 Mar 12]. Available from: https://www.who.int/ mediacentre/news/statements/2009/h1n1_pandemic_phase6_20090611/ en/.

35. Liu Y, Gayle AA, Wilder-Smith A, Rocklöv J. The reproductive number of COVID-19 is higher compared to SARS coronavirus. J Travel Med 2020 Mar 13;27(2). pii: taaa021. https://doi.org/10.1093/jtm/taaa021.

36. Zou L, Ruan F, Huang M, Liang L, Huang H, Hong Z, et al. SARS-CoV-2 viral load in upper respiratory specimens of infected patients. $\mathrm{N}$ Engl J Med 2020;382:1177-9.

37. Bai Y, Yao L, Wei T, Tian F, Jin DY, Chen L, et al. Presumed asymptomatic carrier transmission of COVID-19. JAMA 2020 Feb 21 [Epub]. https:// doi.org/10.1001/jama.2020.2565.

38. Wong SF, Chow KM, Leung TN, Ng WF, Ng TK, Shek CC, et al. Preg. nancy and perinatal outcomes of women with severe acute respiratory syndrome. Am J Obstet Gynecol 2004;191:292-7.

39. Jeong SY, Sung SI, Sung JH, Ahn SY, Kang ES, Chang YS, et al. MERSCoV infection in a pregnant woman in Korea. J Korean Med Sci 2017;32: $1717-20$

40. Chen H, Guo J, Wang C, Luo F, Yu X, Zhang W, et al. Clinical characteristics and intrauterine vertical transmission potential of COVID-19 
infection in nine pregnant women: a retrospective review of medical records. Lancet 2020;395:809-15.

41. Lauer SA, Grantz KH, Bi Q, Jones FK, Zheng Q, Meredith HR, et al. The incubation period of coronavirus disease 2019 (COVID-19) From publicly reported confirmed cases: estimation and application. Ann Intern Med 2020 Mar 10 [Epub]. https://doi.org/10.7326/M20-0504.

42. Wang Y, Wang Y, Chen Y, Qin Q. Unique epidemiological and clinical features of the emerging 2019 novel coronavirus pneumonia (COVID19) implicate special control measures. J Med Virol 2020 Mar 5 [Epub]. https://doi.org/10.1002/jmv.25748.

43. World Health Organization. Report of the WHO-China Joint Mission on Coronavirus Disease 2019 (COVID-19) [Internet]. Geneva (Switzerland): World Health Organization; 2020 [cited 2020 Feb 28]. Available from: https://www.who.int/docs/default-source/coronaviruse/who-chinajoint-mission-on-covid-19-final-report.pdf.
44. Zhao W, Zhong Z, Xie X, Yu Q, Liu J. Relation between chest CT findings and clinical conditions of coronavirus disease (COVID-19) pneumonia: a multicenter study. AJR Am J Roentgenol 2020 Mar 3:1-6 [Epub]. https:// doi.org/10.2214/AJR.20.22976.

45. Wang D, Hu B, Hu C, Zhu F, Liu X, Zhang J, et al. Clinical characteristics of 138 hospitalized patients with 2019 novel coronavirus-infected pneumonia in Wuhan, China. JAMA 2020 Feb 7 [Epub]. https://doi.org/ 10.1001/jama.2020.1585.

46. Chen J. Pathogenicity and transmissibility of 2019-nCoV-A quick overview and comparison with other emerging viruses. Microbes Infect 2020; 22:69-71.

47. Hui DS. Epidemic and emerging coronaviruses (severe acute respiratory syndrome and Middle East respiratory syndrome). Clin Chest Med 2017; 38:71-86. 